\title{
History of the European Computer Driving Licence
}

\author{
Denise Leahy and Dudley Dolan \\ School of Computer Science and Statistics, Trinity College, Dublin, Ireland \\ \{denise.leahy, dudley.dolan\}ascss.tcd.ie
}

\begin{abstract}
The European Computer Driving Licence (ECDL) began as a project which set out to define the computer skills required by the ordinary citizen to take advantage of the new end user technology. The project started in 1995 and since that time ECDL has become the leading digital literacy certification in the world with almost 10 million candidates enrolled in the programme. The core ECDL consists of seven modules, defined by a syllabus which is agreed by an international panel of users and experts and certifies that the holder has the competencies required to perform basic tasks using a personal computer, can use a computer in practice and understands the basic concepts of information technology [1]. This paper describes the creation of the ECDL, together with the unique organizational structure which enabled the wide implementation of ECDL, initially in Europe and later throughout the world as the International Computer Driving License (ICDL).
\end{abstract}

Keywords: Digital Literacy, Certification, IFIP, CEPIS, Basic ICT Skills.

\section{Introduction}

\subsection{The Initial Idea}

With the advent of home computing and the growth in the general use of computers in the early 1990s, the Council of European Professional Informatics Societies (CEPIS) recognised the importance of defining the computer skills required by the ordinary citizen to take advantage of the new technology. The idea originated in Norway and preliminary investigations were undertaken to see what activities were being carried on in this area. The idea was supported by the European Commission and the member societies of CEPIS. CEPIS created a task force in 1995 to examine how to raise the level of such skills in industry throughout Europe [2]. Initially the CEPIS task force consisted of the Nordic countries plus Ireland (Norway, Finland, Sweden, Denmark, and Ireland.) These countries met in 1995 and, after the initial findings were reported to the CEPIS Council, a number of other countries decided to join an extended task force. The extended task force consisted of the original countries plus the new representatives from Austria, France, Italy, The Netherlands and United Kingdom.

This paper describes the history of ECDL from the setting up of the Task Force in 1995 through to the development of ECDL in Europe and later throughout the world. Using material and working papers from that time, it describes the development of 
ECDL, the major milestones and the support given initially by the European Commission and later by Governments, industry and educational bodies.

\subsection{The Links between CEPIS and IFIP}

The International Federation for Information Processing (IFIP) is a non-governmental, non-profit umbrella organization for national societies working in the field of information processing. IFIP was established in 1960, under the auspices of UNESCO, as a result of the first World Computer Congress held in Paris in 1959. This provided a forum for persons involved in the Information Technology area to meet and share ideas [3]. In the 1980s, some of the IFIP member societies based in Europe felt that there was a need for a European organization to meet the local needs of the region and CEPIS was established in 1989 by 8 European informatics societies, CEPIS has since grown to represent over 300,000 informatics professionals in 33 countries. There are many common member societies in IFIP and CEPIS and they communicate and share research and interests at their respective events and meetings [4].

The first area of focus for CEPIS was the promotion and development of information and communications technology (ICT) skills across Europe. CEPIS set out to work closely with the European Commission in order to address the needs of the European Community and meetings were held with Directorates General in the European Commission to establish the areas which CEPIS should pursue. An early venture for CEPIS was the European Informatics Skills Structure which set out to define the skills for ICT professionals in a structured format which could be adopted throughout Europe [5]. This work commenced with the founding of CEPIS in 1989 and work continued until 1996. The project which created ECDL started in 1995.

\section{The Information Society and Digital Literacy in the 1990s}

In 1990, 23 million European households owned a PC and this rose to over 40 million in 1994. However the proportion of European households with a PC was significantly lower than the USA and there were fewer multi-media PCs or those linked to a communications network. Statistics also showed that the speed of adoption of the new technologies highlighted cultural and linguistic differences between Northern and Southern Europe and between the US and Europe [6]. At that time in the United States there were 34 PCs per hundred citizens with the European figure at 10 per hundred.

Advances in information technology substantially changed the workplace in Europe in the mid-nineties. Over $72 \%$ of office workers had a PC or equivalent on their desks and used it as part of their work. At that time there was concern about the future of employment, skills and technology. According to Cortada in 1998 "Each year, on average, more than $10 \%$ of all jobs disappear and are replaced by different jobs in new processes, in new enterprises, generally requiring new, higher or broader skills. There is a much slower pace on the supply side in the acquisition of new skills." [7] He suggested that within 10 years people in employment would be using new technology with out of date skills.

The area of unemployment was recognized as of vital importance, creating a need for retraining. The European Union 1996 report "Living and working in the 
Information Society" advised that "instead of having 9 million people in long term unemployment and de-skilling, the most expensive form of public spending with the lowest return to the economy or the individual, and many more millions on their way to long term unemployment, the Member States of the EU should have 9 million involved in upgrading, maintaining and improving their skills in literacy, numeracy and IT." [8].

In the "90s there was much discussion about the new "Information Society" and the different skills needed by all individuals to take full benefit of what the new society could offer. It was recognized that the new Information Society in Europe would affect everyone. The EU Commissioner Martin Bangemann noted in "The Information Society and the Citizen" that we needed to make "greater efforts" in our schools to prepare the next generation to participate and benefit fully from the Information Society and to stimulate European citizens to create new services in education, entertainment and business in order to keep Europe at the forefront of technology [9].

It was clear that there was a need but it was not clear how to define this. At this time there was talk of computer literacy, digital literacy, end user skills and other definitions. In 1997, Paul Gilster suggested that to be digitally literate a person should be able to find information on line in web sites, databases and other on line information resources, be able to evaluate that information and use email and search engines [10].

It was part of the vision of the CEPIS task force to address the issues raised above and contribute to the successful development of an all inclusive Information Society.

\section{The Beginning}

The Finnish Computer Driving Licence (CDL) was introduced in Finland in January 1994 with the support of the Ministry of Education, the Central Organisation of Finnish Trade Unions, the Confederation of Finnish Industry and Employers, the Finnish Information Processing Association and the Ministry of Labour [11]. The first Computer Driving Licences were awarded in early 1994 and some 10,000 had been issued by December 1995. In 1995, the Finnish Information Processing Association (FIPA) brought the CDL to CEPIS as a potential model for a wider European context.

The CEPIS task force (named the User Skills task force) met in 1995 to consider how to increase the competence required for the European work force and for the European individual. This task force looked for a suitable model and examined the Finnish CDL in detail. There were other models in Europe at that time and these were also examined. After thorough study it was concluded that the basic Finnish concept was widely applicable throughout Europe. However, changes and updates were required - the Finnish model consisted of a bank of questions which they called the "question and test base" but had no defined syllabus [1].

In order to assess the modifications needed to have the ECDL meet the requirements of a wider marketplace, a series of pilot tests were carried out in Norway, Sweden, Denmark, France and Ireland. As a result of these tests and a thorough evaluation of the concept, modifications were agreed. It was decided to name the concept "the European Computer Driving Licence" or "ECDL".

The pilot tests gave an opportunity to evaluate the concept from a number of viewpoints. The pedagogical aspects were considered from the point of view of the breadth 
of knowledge required and the depth needed. The need for the theoretical module was considered and it was decided to retain this. A syllabus was created and a new question and test base was developed to meet these newly defined requirements.

In addition to evaluating the tests themselves, this period of time was used to establish what the market response would be to such a concept. The response was uniformly optimistic although the numerical forecasts varied considerably due to the different levels of penetration of PCs in the different countries. It was clear from the research that industry felt a need for some sort of certification to ensure that their investment in training was worthwhile. Individuals welcomed the opportunity to show that they had acquired computer skills which could be certified. Potential course vendors and training organizations were happy with the concept as it gave them a focus for their course developments. Governmental and employer organizations and Trade Unions in many countries found the concept attractive. In particular, the Irish Congress of Trade Unions (ICTU) was very supportive at a general meeting in Dublin in March 1996 [12]. Ministries of Education in a number of countries gave active support. In Denmark a Government supported regional initiative was undertaken.

The User Skills task force created a syllabus, tests, guidelines and procedures to run ECDL on a European scale. The ECDL certification developed by the task force was a definition of the competencies required to perform basic tasks using a personal computer in order to certify that the holder had the skills required to use a computer and had some theoretical knowledge of computers. The ECDL, similar to the Finnish model, had seven modules. The first ECDL syllabus was published in October 1996 and this represented one of the main outcomes of the work of the ECDL Task Force during 1996. It was expected that the syllabus would be updated on a continual basis and new versions would be issued every year.

Individuals were to prove their proficiency by passing a test within each module with progress registered on a Computer Skills Card. An ECDL was awarded once all seven module tests were passed successfully. Except for one theoretical module, the tests were skills oriented. The tests were independent of both machine and software vendors and products. The infrastructure of CEPIS member societies as licensees to run ECDL within a country was set up. The procedures and rules for setting up Test Centres and for administering, running and marking tests in a standard and consistent way were devised. The legal and contractual issues were identified and put in place.

An initial method for administering the tests automatically by computer was researched in Sweden and this was extensively evaluated. It satisfied many requirements but was not seen to be the final solution to the automation needs in Europe at that stage. This was developed further at a later stage.

\section{ECDL 1997 - 2010}

The European Computer Driving Licence had a number of clearly identified objectives in 1995 as follows [13]:

- To raise the level of IT competence within the work force in industry, commerce and public services throughout Europe.

- To provide a basis for certifying computer skills in all levels of the education sector and provide a basis for certification of skills for lifelong learning. 
- To re-skill the unemployed so that they may re-enter the work force.

- To provide an incentive for the disadvantaged to bridge the gap between the haves and the have not's in the information society.

- To provide an incentive for those outside the work force to develop computer skills.

The ECDL model as created by the task force consisted of four components - the Skills card, the Driving Licence, the Syllabus and the tests. These were described as follows in 1997 [1] as:

- "The European Computer Skills Card records the progress of the candidate and the dates on which each of the seven tests are completed successfully. When all seven modules are completed the candidate is issued with an ECDL. The modules can be taken in any sequence and the tests can be taken in different test centres and indeed in different countries.

- The European Computer Driving Licence is the full licence and indicates that the holder has satisfactorily completed all seven modules. The document has a similar format throughout Europe. It bears the name "European Computer Driving Licence" in English and in the local language.

- The ECDL Syllabus describes the objectives, content and guidelines for assessment of each of the seven modules of the ECDL."

- The European Question and Test Base (EQTB) defines the questions and tests which candidates must pass in order to attain an ECDL."

Module one was the theory test and modules 2-7 were skills tests. Initially there were 100 theory questions and approximately 20 tasks for each of the practical tests. The time allowed and the pass mark for each of the test modules was defined. The first tests defined the following:

- In module one, candidates had to demonstrate an understanding of the basic concepts of IT, answering six questions selected at random, one from each of six sections. The pass mark was $60 \%$.

- In module two "Using the computer and Managing Files" the test consisted of four exercises and the pass mark was $80 \%$.

- The tests for module three "Word Processing" and module four "Spreadsheets" consisted of basic tasks and advanced tasks. The candidate had to complete one exercise consisting of $8 / 10$ tasks. The pass mark was $100 \%$ for the basic tasks and 50\% for the more advanced tasks.

- Two exercises were set for module 5 "Databases/Filing Systems", the first required the candidate to set up a small database for a specific purpose, define the structure of the records and enter data; for the second exercise the candidate had to load a database and answer questions about its contents by constructing queries. The pass mark was $80 \%$.

- For module six "Presentation and Drawing", because of different facilities available to the candidate, one question was asked from either a presentation or drawing section

- Module seven was "Information Network Services" and because, in 1996, not all countries had Internet access, two versions of this test were 
produced - one a test of skill and one theoretical test. The version taken depended on the facilities available. The pass mark was $80 \%$.

\subsection{Quality Assurance}

Quality had a high priority and quality assurance procedures were defined and managed by the ECDL Foundation, the licensees, sub-licensees and the test centres. The quality assurance procedures included use of rigorous authorization guidelines and compulsory standards. The tests for ECDL were conducted by authorized test centres. These centres were validated by the licensee in each country using guidelines provided by the ECDL Foundation. The test centres were expected to be operated by course vendors, educational establishments, large organizations or companies. It was the intention that authorized test centres would provide facilities to test not only their own pupils but also persons who wished to take a test without undergoing formal courses.

The results of the tests in Europe were monitored on a statistical basis and any unusual patterns were investigated by the ECDL Foundation. Strict adherence to the syllabus and the use of the standard tests and marking guidelines also ensured that the tests were of an even standard. The ECDL Foundation performed quality assurance audits to ensure that standards were maintained and that the quality of the product was ensured.

Quality is considered as a continuous improvement element within the organization and today, the ECDL Foundation quality statement is as follows [14]:

"ECDL Foundation is committed to the development, promotion, and delivery of quality certification programmes so as to enable proficient use of ICT that empowers individuals, organisations and society throughout the world.

To meet the needs of all our customers, ECDL Foundation has established a Quality Management System based on the internationally-recognised quality standard ISO 9001: 2000.

Adherence to this standard ensures that the processes used by ECDL Foundation to develop and support its certification programmes, are effective, efficient, and subject to continuous evaluation and improvement."

\subsection{Accessibility}

In early 2001, accessibility was identified as a major requirement for ECDL. The ECDL Foundation was a partner in an accessibility project, ECDL-PD, which planned to examine ECDL, identify accessibility issues and propose solutions. The outcome of this project [15] was the definition of potential barriers to inclusion within ECDL. At the same time other projects examined accessibility issues; these included projects in the UK, Hungary, Italy, Austria [16] and Greece. The ECDL Foundation set up an international working group, which included representatives of disability groups, to decide on how to address the identified barriers and to collate the results and findings. These were used these to inform future development, procedures and standards [17].

ECDL is committed to accessibility and inclusion. Today, the Accessibility Statement on the web site reads: 
"ECDL Foundation is committed to ensuring that no one is excluded from pursuing our certification programmes and actively works to maintain the accessibility of our programmes to all, including people with disabilities. We have been working with our national operators and with disabilities groups to identify and eliminate major barriers to the accessibility of ICT skills and will continue as part of the ongoing enhancement of ECDL Foundation's programmes."

\subsection{Development and Updating}

The ECDL Foundation set up a Members Forum which gave a platform for licensees, sub-licensees and test centres to share experiences and to suggest developments which they felt were appropriate. This ensured that the products were updated and developed in line with advances in technology and market requirements. The ECDL syllabus and EQTB were updated on a regular basis by an international panel of subject matter experts, ECDL licensees, end users and companies.

\subsection{Automation}

A priority in 1997 was to ensure that the testing process was automated to the fullest possible extent. This was seen to be vital in the light of the expected volumes of ECDL candidates planned to be some hundreds of thousands initially and ultimately would be millions. The feasibility of taking tests over the Internet from work or home was also be investigated as were diagnostic tests which pointed to the areas of weakness of each candidate rather than the pass/fail testing process [1].

\subsection{ECDL Products and Programmes}

There was a window of opportunity for the core ECDL at that time in 1997. It was hoped that it would quickly gain acceptance as the test of skills in Europe. There were early optimistic signs that this would be achieved. The support of the European Commission through funding from the ESF (European Social Fund), DGIII and DGXXII gave the ECDL considerable credibility. In addition, ECDL was included in the Information Society Action Plan prepared by Commissioner Bangemann for Central and Eastern European Countries [18].

Countries outside Europe began to take an interest in ECDL in 1998. In these countries ECDL runs as ICDL (International Computer Driving License). The syllabus, procedures, test methods and certification remain exactly the same. The first ICDL was presented to a young woman in Port Elizabeth in South Africa in 1999 [19].

The ECDL which has been discussed in this paper is the core ECDL which is identified today as an ECDL programme - "Essential Computer Skills". ECDL now offers many other programmes. The first to be developed was the advanced ECDL, which was proposed by the Danish computer society in 1999. Programmes developed over the last ten years include e-Citizen and Equalskills - these comprise programmes on "Internet and email" and "computers for beginners", respectively. These programmes fall within the digital literacy categories. Other specialist programmes include Computer Aided Design (CAD), Website creation, Health Informatics and Digital Imaging. 


\section{The Scope of the ECDL Potential Population 1997 - 2010}

Who should benefit from ECDL? The potential users for the ECDL products and services could be seen from several viewpoints, such as geographical, by population sectors, and specifically the work force. The following statistics are taken from the plans presented to the European Commission in 1997 on the setting up of ECDL [20].

\subsection{Geographical Scope}

The market for ECDL was those countries which were defined as being European by virtue of their membership of the Council of Europe. The Member Societies of CEPIS were present in 17 of those countries in 1996 with a total of some 250,000 computer professionals. The CEPIS Member Societies represented channels to a major part of the overall market. CEPIS was represented in the following countries: Austria, Cyprus, Denmark, Finland, France, Germany, Greece, Hungary, Ireland, Italy, Netherlands, Norway, Poland, Spain, Sweden, Switzerland, and UK. The potential market was all of the wider Europe. This included the then 15 Member States of the EU, the three Associated States (Norway, Liechtenstein and Iceland), Switzerland, and the then twelve applicant states (Latvia, Estonia, Lithuania, Poland, Hungary, the Czech Republic, Slovakia, Bulgaria, Romania, Slovenia, Cyprus, Malta). Altogether this added up to 31 countries, which was the number of countries that were addressed in the proposed business and implementation plans for the ECDL at that time.

\subsection{Population Sectors}

The total population in the 31 countries was about 500 million. Divided in sectors, the numbers were very roughly as follows:

1 the employed work force

2 the education sector

3 the unemployed

4 the socially disadvantaged

5 people outside the work force
200 millions

100

25

15

$160 \quad$ (not unemployed)

ECDL was relevant to the all users throughout the population. However, it was felt that the Business Plan had to focus on selected parts of the total market. In accordance with the initial objectives, the first ECDL Business Plan primarily addressed the needs and potential in the European workforce.

\subsection{The Work Force Sector}

The workforce definition varied considerably across the geographical area in question. Very generally, one could have used the following assumptions:
Workforce (employed, $40 \%$ of Total Population)
200 million
Non-manual workers $(60 \%)$
120 million
Knowledge/information workers (50\% of above)
60 million 
At the time of the development of ECDL it was believed by the task force that computers were used by some $50 \%$ of the workforce. Thus, as an order of magnitude, it was not unreasonable to assume that some 60 million European workers should be competent at least at a basic IT-user level, in order to utilise the investments in information technology and systems. It was a fact that most of these millions of users had become IT-users over very few years and that most of the users had received little or no IT-training in their schooling or education before they entered the work force. At this time, the European workforce probably faced the largest retraining and adult education challenge ever. ECDL addressed exactly this challenge by defining a basic skill level and by offering mechanisms to entice users, employers and organizations to raise the skill level of the individuals in the work force. It was acknowledged that these needs could not be met in the very short term.

\subsection{Today}

ECDL has grown worldwide with 9.7 million candidates and 121 active countries by November 2009. This growth is shown in Figure 1 below.

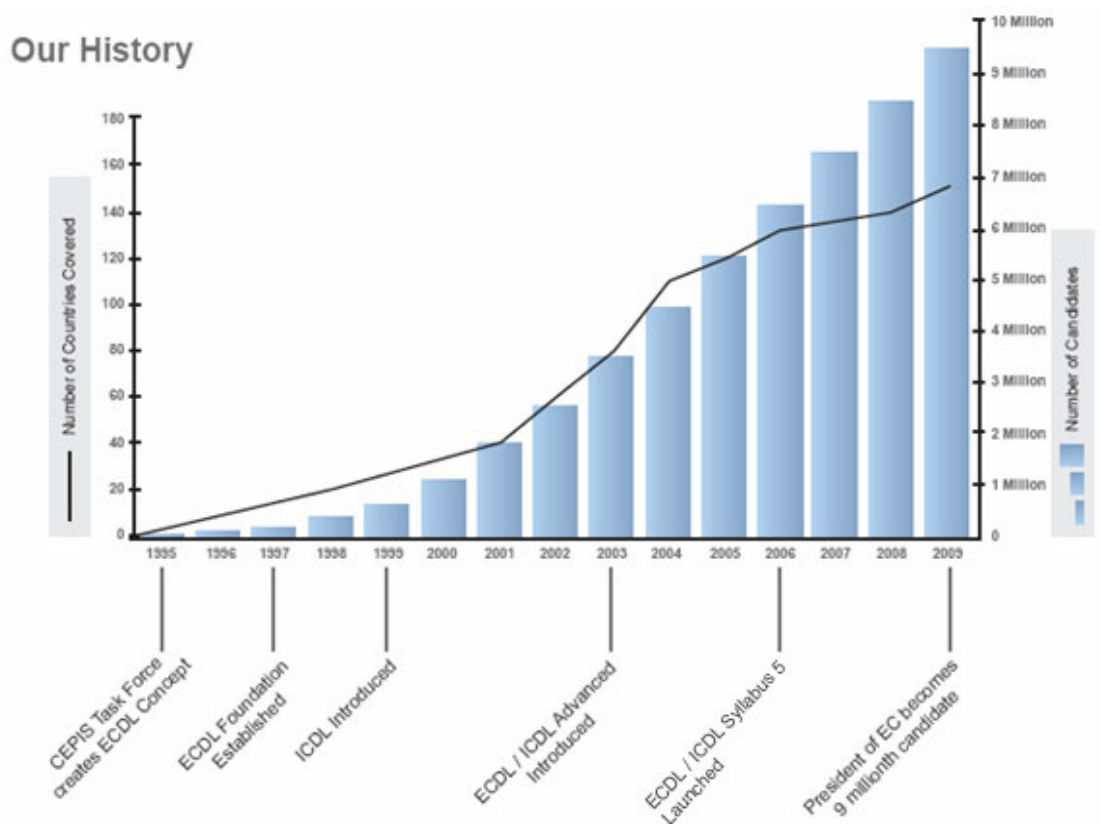

Fig. 1. Timeline and history of ECDL ${ }^{1}$

\section{Organisation}

The ECDL Foundation was set up in Ireland as a Company limited by guarantee, having no share capital. Following legal advice this model was selected as being the

\footnotetext{
${ }^{1}$ http://www.ecdl.org/publisher/index.jsp?p=94\&n=170
} 
most suitable to meet the needs for implementing ECDL throughout Europe. It gave protection to the members, being the Member Societies of CEPIS, as well as allowing the organisation to function as a business with charitable objectives. All surplus revenues were retained within the Company and used to further the objects of the Company as set out in the Memorandum and Articles of Association.

The licensees became members of the ECDL Foundation and are the controlling body. They elect the board of the ECDL Foundation at the Annual General Meeting. The Board of the ECDL Foundation consists of a maximum of seven persons elected at the General Meeting.

It was decided to locate the ECDL Foundation in Dublin because of the infrastructure in that country for supporting the Software Industry. The tax arrangements were potentially attractive and some grants had been secured to help finance the initial set up costs of the ECDL Foundation. The ECDL Foundation needed a very skilled and motivated staff, in order to succeed with the ambitious goals and plans for the organisation. The skills included solid IT, educational and pedagogical backgrounds, combined with marketing, business and administrative experience. Experience with international work and co-operation was also an absolute requirement. As detailed in the first implementation plan, the ambition levels required $4-8$ staff for the 5-year plan period. It was planned that the ECDL Staff in Dublin would have a central capacity of 3 early in 1997, and then increase to 4 . Other people resources would be recruited on a consulting basis from the other ECDL Foundation Member countries, in order to encourage use of Best Practices within the ECDL community. This model ensured flexibility and transfer of knowledge [21].

\section{Conclusions}

ECDL has gained a reputation as a standard for digital literacy in many countries. The largest adopters of ECDL in total numbers are the UK and Italy. In the latter, all school children undergo training in ECDL. In both countries the Government Departments of Education provided funding in various ways. ECDL also performs well in a social sense being used in prisons in Austria and in Refugee Camps in Gaza. The largest penetration per head of population is in Ireland where over 10\% of the working population has achieved ECDL.

ICDL continues to be successfully implemented throughout the world, most recently being adopted in Kenya where the Information \& Communications Minister announced that ICDL is to be the sole government recognised entry level computer certification with which to demonstrate competence in computer usage. ICDL has been adopted in Jordan where all teachers must achieve the ECDL and by UNDP as a standard for the training of staff throughout the development programme.

The success of ECDL is due to many factors which have contributed to its acceptance throughout the World. Initially the word "European" in the title helped to give the certification a degree of credibility before it was widely recognised. Also the fact that it was included as one of the 27 projects in "Towards the Information Society Twenty-seven ideas for European Initiatives" at a time when the European Union was preparing for expansion was extremely helpful [22]. ECDL was developed and disseminated initially through Member Societies of CEPIS which was important in 
gaining acceptance by Governmental bodies. The ethos and professional standing of the Member Societies added credibility to the certification and ensured that quality and standards were maintained at all times.

In 1995, the project which created ECDL set out to define the knowledge and skills which were needed with the arrival of the new end-user technology. Today, digital literacy is becoming more important and the ECDL programmes continue to develop and address the changing needs for such knowledge and skills.

\section{References}

1. User Skills Task Force, Esprit project documents and working papers (1995-1997)

2. Occhini, G.: ECDL the Take off years, Upgrade (4) (August 2009), http: / /www. cepis-upgrade.org/issues / 2009/4/up10-40cchini.pdf (accessed February 9, 2010)

3. IFIP, The International Federation for Information Processing, http: / /www.ifip.org/index.php?option=com_content\&task=view\&i $\mathrm{d}=56 \&$ Itemid $=110$

(accessed February 10, 2009)

4. Council of European Professional Informatics Societies, http: / / www . cepis.org/index.j.sp?\&p=636\&n=637 (accessed May 10, 2010)

5. Berleur, J., Brunnstein, K.: European Informatics Skills Structure (EISS - CEPIS) code of professional conduct. In: Ethics of Computing: Codes, Spaces For Discussion and Law, pp. 175-176. Eds. Chapman \& Hall Ltd., London (1996)

6. Bangemann, M.: Europe and the Global Informations Society (recommendations to the European Council) (1994)

7. Cortada, J.W.: The Rise of the Knowledge Worker. Butterworth-Heinemann, Butterworths (1998), ISBN: 978-0-7506-7058-6

8. Bangemann, Living and working in the Information Society (1996), http: / / www . uni-mannheim. de/edz / pdf / kom/gruenbuch/kom-19960389-en.pdf (accessed February 9, 2010)

9. Bangemann, M.: The Information Society and the Citizen, http: / /ec.europa.eu/information_society/index_en.htm

10. Gilster, P.: Digital literacy. John Wiley, Chichester (1997), ISBN 0471165204

11. Computer Driving License to the rescue, http: / /www.e.finland.fi/netcomm/news/showarticle3511.html?in tNWSAID $=40488$ (accessed February 9, 2010)

12. Irish Congress of Trade Unions, open meeting held in Dublin (March 1996)

13. Carpenter, D., Dolan, D., Leahy, D., Sherwood-Smith, M.: ECDL/ICDL: a global computer literacy initiative. In: 16th IFIP Congress (ICEUT200, educational uses of information and communication technologies), Beijing, China (2000)

14. The ECDL Foundation, http: / / www . ecdl.org/publisher/index.jsp?p=94\&n=609 (accessed May 10, 2010)

15. Petz, A., Miesenberger, K.: ECDL- PD - Using a Well Known Standard to Lift Barriers on the Labour Market. Springer, Heidelberg (2002), 978-3-540-43904-2

16. ECDL barrierfrei, http: / /www. epractice.eu/en/cases/ecdlbf 
17. Leahy, D., Dolan, D.: Making an International Certificate Accessible. In: Miesenberger, et al. (eds.) Computers Helping People with Special Needs, 11th edn., Linz, Austria, pp. 1313-1320. Springer, Heidelberg (2008)

18. Public strategies for the Information Society in the member states of the European Union, http: / / www. ecdl . com. cy/assets/mainmenu/131/docs / EUMemberStatesStrategies .pdf (accessed May 10, 2010)

19. Dolan, D.: In: Marshall, G., Ruohonen, M. (eds.) Capacity building for IT in education in developing countries. Chapman and Hall, Boca Raton (1998)

20. Presentation to European Commission, Brussels, Internal Working Document, Members of the User Skills Task Force (February 1997)

21. Johnson, R.: ECDL is launched - now what?, Upgrade (2009), http: / /www. cepis-upgrade.org/

22. Towards an European Information Society Major EU Initiatives, (1996) http: / / www . euro.ubbcluj .ro/ htodoran/articles/articoll.html (accessed February 9, 2010) 